\title{
Hierarchical ordering of nests in a joint mode and destination choice model
}

\author{
Jeffrey P. Newman • Vincent L. Bernardin Jr.
}

Published online: 17 April 2010

(C) Springer Science+Business Media, LLC. 2010

\begin{abstract}
This paper seeks to explore the relationship between mode and destination choice in an integrated nested choice model. A fundamental argument can be made that in certain circumstances, the ordering of choices should be reversed from the usual sequence of destination choice preceding mode choice. This results in a travel demand model where travelers are more likely to change destinations than to change transportation modes. For small and medium size urban areas, particularly in the United States, with less well developed public transit systems that draw few choice riders, this assumption makes much more sense than the traditional modeling assumptions. The models used in the new travel modeling system developed for Knoxville, Tennessee utilize this reversed ordering, with generally good results, which required no external tinkering in the logsum parameters.
\end{abstract}

Keywords Discrete choice models · Mode choice · Destination choice · Demand $\cdot$ Elasticity $\cdot$ Hierarchical nesting $\cdot$ Integrated models

\section{Background}

Trends in transportation demand modeling are moving away from the traditional sequential four-step model toward more integrated models, which combine multiple levels of personal transportation decision processes. Integrated models combine related choices, including destination, mode, and route decisions, into a single consistent modeling framework. It has been known for some time that jointly estimated models for multiple dimensions of behavior choices need to be a part of travel models, as fully separated conditional choice models can give incorrect or misleading results (Ben-Akiva 1974; Richards and Ben-Akiva

\footnotetext{
J. P. Newman $(\square)$

École Polytechnique Fédérale de Lausanne, ENAC TRANSP-OR, GC B3 445 (Bât. GC), Station 18, 1015 Lausanne, Switzerland

e-mail: jeffrey.newman@epfl.ch

V. L. Bernardin Jr.

Bernardin, Lochmueller \& Associates, Inc., 6200 Vogel Road, Evansville, IN 47715, USA

e-mail: vbernardin2@blainc.com
} 
1974). The relationships between choices have been found to be relevant in a number of transportation decisions, both long term decisions involving housing and car ownership (Lerman 1976), and short term decisions on activity and destination choice (Kitamura and Kermanshah 1984), and mode and route choice (Vrtic and Axhausen 2002).

Activity-based models, which consider travel decisions as a by-product of activity participation decisions, are an advanced form of integrated model, which jointly consider both activity participation and travel related choices. A seminal activity model presented by Bowman and Ben-Akiva (2001) represented activity patterns, time of day, destination and mode choices as a massive nested logit model, with a cascading sequence of nesting structures. Yet even less sophisticated models can benefit by integrating model components (Boyce 2002; Bernardin 2008).

Most operational integrated travel demand models employ a sequential estimation of model components, passing information up from lower level model nests in the form of an inclusive value (i.e., logsum) (Miller et al. 2005). This essentially embodies a limited information maximum likelihood (LIML) approach to model estimation. Such estimation is statistically inefficient compared to a full information maximum likelihood (FIML) approach that handles all aspects of the choice simultaneously (Hensher 1986). Unfortunately, the combinatorial explosion in the number of discrete choices when all aspects of activity and travel choices are considered together makes such full information estimation intractably large for most communities. A handful of operational models make partial steps towards FIML by estimating both destination and mode choices together (Bradley and Bowman 2006), although to truly be a full information model, all of the information on all aspects of travel choices should be included, not just for the mode and destination aspects of the choice.

Regardless of the simultaneous or sequential nature of the parameter estimation process, the form of the entire integrated choice model determines the resulting demand elasticities. When inclusive values are passed between model segments in a manner consistent with a utility maximizing nested logit model, the layout of the nests uniquely determines the relative magnitudes of the elasticities (Koppelman and Wen 1998). Thus, choice of model form, and ordering of the nesting hierarchy, imposes a priori a particular cross-substitution pattern that may or may not be reflected in the data.

The relationship between mode and destination

While fundamentally different from a traditional four-step model, in practice an integrated model framework generally adopts a hierarchical structure that mimics that of the four steps, at least in the ordering of decisions. Within the hierarchy, the combined model typically incorporates the destination choice as a higher level decision than the mode choice (Boyce 2002; Jonnalagadda et al. 2001; Siegel et al. 2006; Yagi and Mohammadian 2008).

An advantage of this ordering, where mode choice is modeled conditional on (after) destination choice (or distribution), is that the mode choice models can more easily use actual travel times between origins and destinations as level-of-service variables. Complete, simultaneous models of mode and destination choice can use this information with either ordering, but creating and estimating such models is time consuming and expensive, and as noted earlier is often avoided in operational models. Constructing such models for practical application may become reasonable in the future, but for now the sequential method is generally preferable for production work.

The history of the traditional model structure is not well defined (Boyce 2002), but it is clear that it was first developed for very large metropolitan areas with significant choice 
rider markets. As such, it is sensitive to changes in level-of-service provided by transit improvements and is useful for testing their impacts on transit route ridership. However, it may be oversensitive to level-of-service variables and a source of optimism bias in transit forecasts, as this model structure is built on the assumption that travelers are more likely to change mode than destination. This may well be the case for affluent choice riders for their work commute in large cities; however, there are many situations in which it seems more reasonable to assume to the contrary, that travelers are more likely to change destinations than mode.

The assumption on elasticities (whether travelers would be more likely to change mode or to change destination) is an outcome of the ordering of the hierarchy of choices, and the framework of the underlying utility maximization theory. In particular, in order to create a nested hierarchical model that is consistent with utility maximization theory, the parameters on the logsums of the lower level nests must be smaller than the parameters higher up, inducing a greater level of cross-substitution among alternative in the lower level nest. By reversing the order of the models, we reverse the hierarchy of the nests. As this hierarchy enforces the form of the elasticities, it is the modeler's assumption in choosing the framework of the model that determines this, and not any outcome of the model estimation process utilizing the underlying data.

Only a few studies have examined a reversed hierarchy, with the destination choice nested below the mode choice. Abrahamsson and Lundqvist (1999) proposed such a model for Stockholm, and found that while the normal nesting structure had a slightly better overall goodness of fit than the reverse structure, the estimated parameters on the logsum values for the nests were not valid. As a result, the cross-elasticities of some parts of the normal model were positive (so that if a single alternative was made more attractive, that would cause an increase in the probabilities for some other alternatives). For a single choice model by itself, this is not consistent with utility maximization, and the authors correctly point out that most modelers would discard such results out-of-hand. For choices within a broader context, such as stop locations on a connected tour, such elasticities may occur through agglomeration or complementarity effects, as noted in Bernardin et al. (2009).

In a similar vein, Debrezion et al. (2009) constructed a model for the joint choice of access mode to the rail system and the train station used by Dutch railway users. They found that a nesting structure with access mode choice on top and railway station choice underneath (i.e., the reverse structure) provided a valid nested logit model with their data, while the normal ordering did not.

In this paper, we examine the reverse hierarchy as applied to Knoxville, Tennessee. Knoxville is substantially different from Stockholm and Holland, and much more representative of the archetypical small to medium sized American city. In particular, transit usage makes up only a very small percentage of the total trip making in Knoxville, and choice riders on the existing transit system are few and far between. Within the context of such an auto-dominated community, it is even more likely that travelers will be more reluctant to switch modes (in particular, to give up driving) than to switch destinations.

\section{Data}

For this study, we are conducting an analysis on travel data collected in Knoxville, Tennessee. The data used is from the 2000 Knoxville Urban Area Household Travel Behavior Study, a prompted recall survey of 1,538 households in Knox and Blount counties (NuStats 
2001); and from the 2008 East Tennessee Household Travel Survey, covering an additional 1,400 households in Knox and Blount as well as the collar counties to supplement the original survey in 2000 (NuStats 2008). In addition, Knoxville Area Transit (KAT) conducted a small on-board survey in September of 2008. Weights were developed in order to combine the three surveys and the models were estimated from the combined dataset.

The models described in this paper constitute a part of the new Knoxville Regional Travel Model. In that regional model, as in most activity-based models but uncommonly in trip-based models, the mode of travel is modeled in two stages: tour mode choice and trip mode choice. For the purposes of the analysis here, we will only examine the tour mode choice. The Knoxville model makes use of four primary modes in tour mode choice:

- Private automobile,

- Public transit,

- Walk/Bike, and

- School bus.

The primary mode or 'tour mode' for a tour is determined by a simple set of definitions or rules.

1. Any tour containing a school bus trip is a school bus tour.

2. Any other (non-school bus) tour containing a public transit trip is a public transit tour.

3. Any other (non-transit) tour containing a private automobile trip is an automobile tour.

4. Any other tour, which contains only walk or bike trips, is a walk/bike tour.

In this framework, the primary choice determining major mode shares is tour mode choice. Trip mode choice ultimately reduces mostly to the determination of vehicle occupancy for automobile tours or the allocation of access modes for transit tours.

\section{Models}

The focus of this work was to develop an operational transportation forecasting model for the Knoxville region. Models were created to forecast a wide variety of travel purposes, including work, school, maintenance and discretionary activities. In this paper, we limit our examination to work tours, which constitute a large fraction of travel. The specific parameters and variables used to model other types of travel are different, but the same general structure of choice modeling applies, and the relevant findings (in particular, the ordering of the choice hierarchy) for other types of travel do not differ from those for work travel.

Local household survey and KATS on-board survey data offer some support of the general assumption for the Knoxville region that travelers are more likely to change destination than mode of travel. In general, this assumption seems more appropriate in markets like Knoxville with few choice riders where mode choice is generally a foregone conclusion upon which destination choice is conditioned (i.e., either the traveler has access to a car and does not even think of riding transit or they do not have access to a car and rely on transit, choosing their destinations, possibly even workplace, based on where the transit system can get them). "Reverse hierarchy" models such as those in the Knoxville Regional Travel Demand Model, which represent destination choice conditional on mode choice, still take the level-of-service provided by competing modes into account and allow for changes in ridership based on improvements to transit or highway modes. However, they measure the level-of-service provided by each mode not directly by the travel times 
between origins and destinations but indirectly by the accessibility to various types of destination provided by each mode to a residence zone.

The accessibility variables used in the tour mode choice are logsums based on a relatively simple version of the utility of the stop location choice models, which includes only the impedance and attraction (or size) variables (consistent with simpler destination choice models than were actually used). The stop location choice models were estimated first and the inclusion of these accessibilities as proxy variables for their expected utility in the tour mode choice models allows for the interpretation of the two component models as a single nested logit model of the combined choice of tour mode and stop location. There is some loss of statistical efficiency in estimating the models sequentially in this manner, rather than simultaneously. The combination of these two models in this fashion allows for reciprocal sensitivity of mode choice to destination choice as well as vice versa but at the cost of requiring the feedback of these accessibility variables in addition to travel times in the model application.

In the ideal case, these models would be estimated using a FIML procedure, as opposed to the sequential procedure described here, as the FIML can provide superior results (Hensher 1986). However, such a model would require a multiplicatively large number of elemental alternatives, with one alternative for every destination by mode pairing. Unfortunately, the resources available for the Knoxville model did not allow computing models of such scope. Sampling alternatives to reduce the computational burden could also be considered, but sampling has different drawbacks; in a nested logit model sampling does not guarantee consistent parameter estimates, and can require reasonably large sample sizes to achieve quality results (Nerella and Bhat 2004).

The results of the model estimation from the combined household survey data and incorporating observations from the KATS on-board survey, performed using ELM software (ELM-Works 2009) and presented in detail below, provide some specific evidence for the reverse hierarchy and the assumption that travelers in the region are more likely to change destinations than mode. This claim is based on the fact that the sequentially estimated maximum likelihood parameter on the logsum accessibility variable lies within the acceptable range (i.e. between zero and the parameter on the nest of modes above). This fact stands in rather stark contrast to the combined mode and destination choice models of the traditional hierarchy which may require the constraint of the mode choice logsum parameters in destination choice-equivalent to the imposition by fiat of the assumption that travelers are more likely to change mode than destination. The Knoxville models imposed no such behavioral assumption, in contrast, their "reverse" assumption on the magnitude of the mode and destination choice elasticities was simply supported by the data.

\section{Mode choice}

The choice of primary mode for work tours was modeled using a nested logit model, grouping the private automobile and public transit alternatives together as motorized modes, as shown in Fig. 1. Although the estimated nesting coefficient was not statistically significantly different from one, it was judged to be different enough to justify the nesting structure, especially in light of the relatively small transit rider population. This structure implies that people who drive to work are more likely to switch to take a bus than to walk/ bike and transit riders are more likely to switch to driving than to walking/biking. This seems reasonable, particularly for work tours when travel time is more important, 


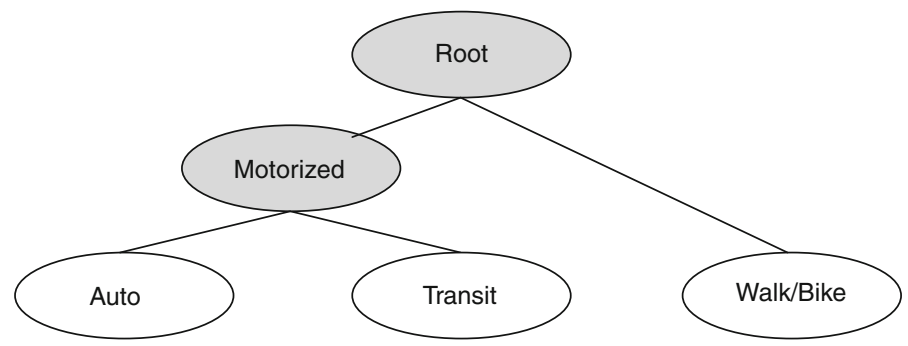

Fig. 1 Nested model for mode choice for work and other tours

suggesting that workers who commute by foot or by bike are different or special in some way, likely in that they live very close to work.

As seen in the estimated parameters for work tour mode choice shown in Table 1, the parameter on accessibility was unsurprisingly highly significant, implying that the level-ofservice (travel times) provided by the competing modes are important in the choice among

Table 1 Disaggregate nested logit model of work tour mode choice

\begin{tabular}{|c|c|c|c|}
\hline Variable & Alternative & Parameter & $t$-Statistic \\
\hline \multicolumn{4}{|l|}{ Logsum parameters } \\
\hline Motorized nest & Auto, Transit & 0.5262 & -0.42 \\
\hline \multicolumn{4}{|l|}{ Generic parameters } \\
\hline Logsum accessibility of gravity work location choice & All & 0.0457 & 3.14 \\
\hline \multicolumn{4}{|l|}{ Alternative specific parameters } \\
\hline Constant & Transit & -0.0169 & $*$ \\
\hline Constant & Walk/Bike & -5.1936 & $*$ \\
\hline Household students & Transit & -1.3181 & -2.98 \\
\hline Presence of seniors in household & Transit & -0.7682 & -1.37 \\
\hline Presence of seniors in household & Walk/Bike & -0.7682 & Constrained \\
\hline Income group (1-3) & Walk/Bike & -0.7381 & -2.18 \\
\hline Gas price (year $2006 \$$ ) & Auto & -0.1150 & $* *$ \\
\hline Bus fare (year $2006 \$$ ) & Transit & -0.0690 & $* *$ \\
\hline Activity diversity & Walk/Bike & 3.0949 & 1.63 \\
\hline Percent of zone's streets with sidewalks & Walk/Bike & 2.8035 & 4.03 \\
\hline Household vehicles per person & Transit & -2.3673 & -5.69 \\
\hline Household vehicles per person & Walk/Bike & -1.259 & -1.82 \\
\hline \multicolumn{4}{|l|}{ Model statistics } \\
\hline Log likelihood at zero & & -3074.2 & \\
\hline Log likelihood at constants & & -205.1 & \\
\hline Log likelihood at convergence & & -148.0 & \\
\hline Rho-squared w.r.t. zero & & 0.952 & \\
\hline Rho-squared w.r.t constants & & 0.278 & \\
\hline
\end{tabular}

* Constants were adjusted in calibration in order to reproduce observed mode shares; the original estimated constants were 0.2196 and -4.9641 for Transit and Walk/Bike, respectively

** Parameters for gas price and bus fare were constrained in calibration in order to produce elasticities consistent with observations. Original estimated parameters were larger in magnitude and highly significant 
them. The number of household students decreased the probability that workers would commute by bus, suggesting the need or desire to drop children off at school, which is more easily facilitated by private auto. The presence of seniors marginally decreased the probability of transit and walk/bike modes for commuting (e.g., in the case of senior workers, an increased effort/cost associated with walking, generally necessary to access transit, as well). This variable was retained in the model, even though it was not particularly statistically significant in the final model estimation, as it exhibited higher significance in a variety of other specifications. Higher income levels were found to decrease the probability of walking/biking to work but did not have any significant impact on bus use once the level of vehicle ownership was taken into account. The number of household vehicles per person decreased both the probabilities of transit and of non-motorized modes. Considering cost variables, higher gas prices decrease the probability of private automobile use and higher bus fares decrease the probability of bus use, as expected. Built environment variables (for the residence zone) including activity diversity (mixed land uses) and the percent of streets with sidewalks increased the probability of walking or biking to work. Overall, the model's goodness-of-fit statistics suggest that the model does a good job explaining commuting mode choices in the region, but much of the behavior is explained by the models constants which correspond to travelers' biases regarding unobserved or unquantifiable characteristics of the modes.

\section{Location choice}

The stop location choice models for the Knoxville Regional Travel Model incorporate the effects of various impedances, not only travel times but also the psychological boundary represented by political boundaries and river crossings, the effects of traditional attraction or size variables such as employment, enrollment, etc., as well as the effects of other destination qualities such as their accessibility to complements and to substitutes, their degree of activity diversity (mixed uses) and the cost of parking and the effects of traveler characteristics such as income or the centrality (accessibility) of their residence.

Most of the effects are incorporated in the model by adding terms to the utility function. However, the traveler heterogeneity effects related to income and residence location are handled differently. Analysis of average travel times from home to stop locations of the various types by income group indicated that the only statistically significant difference was between low income and other work locations. Income was therefore simply used to segment the model and estimate separate work location choice models for low income workers and other workers.

The incorporation of the accessibility of travelers' residence location reflects the fact that when people choose their residence location, they also effectively choose how far they are willing to travel. Travelers who live in dense, urban (high accessibility) areas are likely to have shorter trip lengths than travelers who live in remote, rural (low accessibility) areas. In the stop location choice models developed here, travelers' willingness-to-travel, and hence, trip lengths, vary as a function of the accessibility of their residence. In general, the willingness-to-travel of residents of the most urban (most accessible) areas was about $10 \%$ lower than the regional average; whereas, the willingness-to-travel of residents of the most rural (least accessible) areas was about $200 \%$ higher or twice the regional average for most stop types. The travel times which are interacted with residence accessibility do include terminal times, generally assumed at $2 \mathrm{~min}$, except for the downtown areas with pay parking where the terminal time is assumed to be $4 \mathrm{~min}$. 
Table 2 Work location choice model for low income households

* One size/attraction variable must be constrained (not all can be identified)

** The willingness-to-travel parameter was adjusted in calibration, the original value was $-0.0114,(t$-stat 15.89$)$

*** The intrazonal parameter was adjusted in calibration; the original estimated parameter was 0.0875

\begin{tabular}{lll}
\hline Variable & Parameter & $t$-Statistic \\
\hline Size parameters & & \\
$\quad$ Basic employment $\left(\mathrm{A}_{1 \mathrm{j}}\right)$ & 1 & $*$ \\
Industrial employment $\left(\mathrm{A}_{2 \mathrm{j}}\right)$ & 1.0037 & 1.61 \\
Retail employment $\left(\mathrm{A}_{3 \mathrm{j}}\right)$ & 1.3761 & 2.36 \\
$\quad$ Service employment $\left(\mathrm{A}_{4 \mathrm{j}}\right)$ & 1.3893 & 2.46 \\
$\quad$ Generic parameters & & \\
Travel time $\times$ residence accessibility $\left(\mathrm{a}_{0 \mathrm{~h}} \mathrm{t}_{\mathrm{hj}}\right)$ & -0.0137 & $* *$ \\
River crossings $\left(\mathrm{x}_{1 \mathrm{hj}}\right)$ & -0.4159 & -2.87 \\
County line crossings $\left(\mathrm{x}_{2 \mathrm{hj}}\right)$ & -0.4405 & -3.27 \\
Percent of destination zone within & 1.1906 & 4.58 \\
$\quad 1 / 2$ mile of bus $\left(\mathrm{x}_{3}\right)$ & 0.4872 & $* * *$ \\
Intrazonal $\left(\mathrm{x}_{0}\right)$ & & \\
Model statistics & -3725.4 & \\
Log likelihood at zero & -2908.0 & \\
Log likelihood at estimation & -2940.6 & \\
Log likelihood at application & 0.211 & \\
Rho-squared w.r.t. zero &
\end{tabular}

The travel time, interacted with residence accessibility as described above, was found to be highly significant in both the low income (Table 2) and other work location choice models (Table 3 ) indicating that all travelers prefer work locations closer to home, but urban residents do more so than rural residents. River crossings and county line crossings were also found to decrease the utility or attractiveness of a location, acting as additional impedance variables. Based on the value of (travel) time for travelers residing in average accessibility areas, a river crossing was equivalent to an additional $3.3 \mathrm{~min}$ of travel time for low income workers or 0.9 min for other workers and a county line crossing was equivalent to approximately an additional $3.5 \mathrm{~min}$ of travel time for workers (regardless of income).

The work location choice model for low income workers also shows that zones with greater access to KATS bus routes are more attractive work locations for these workers. This stands to reason, as low income workers are less likely to own cars and more likely to depend on public transit service for transportation, making locations served by transit more attractive.

The work location choice model for other workers incorporated the general accessibility of destinations as a variable, making it a competing destinations model (Fotheringham 1983, 1986). The highly significant positive parameter associated with this variable indicates significant agglomeration effects, or in other words, that work locations near other work locations (such as those in downtown Knoxville) are generally more attractive than isolated locations for middle and higher income workers.

Both work location choice models for low income and other households are statistically superior to gravity models, but are still limited in explanatory power without more detailed information about the precise industries at locations and the income/occupations of workers. 
Table 3 Work location choice model for middle and upper income households
* One size/attraction variable must be constrained (not all can be identified)

** The willingness-to-travel parameter shown was adjusted in subsequent calibration, the original value was $-0.0101,(t$ stat 33.24)

*** The intrazonal parameter was adjusted in calibration; the original estimated parameter was $-0.131$

\begin{tabular}{lll}
\hline Variable & Parameter & $t$-Statistic \\
\hline Size parameters & & \\
Basic employment $\left(\mathrm{A}_{1 \mathrm{j}}\right)$ & 1 & $*$ \\
Industrial employment $\left(\mathrm{A}_{2 \mathrm{j}}\right)$ & 2.0928 & 5.74 \\
Retail employment $\left(\mathrm{A}_{3 \mathrm{j}}\right)$ & 1.2212 & 3.15 \\
Service employment $\left(\mathrm{A}_{4 \mathrm{j}}\right)$ & 2.2137 & 6.26 \\
Generic parameters & & \\
Travel time $\times$ residence accessibility $\left(\mathrm{a}_{0 \mathrm{~h}} \mathrm{t}_{\mathrm{hj}}\right)$ & -0.0103 & $* *$ \\
River crossings $\left(\mathrm{x}_{1 \mathrm{hj}}\right)$ & -0.1038 & -1.92 \\
County line crossings $\left(\mathrm{x}_{2 \mathrm{hj}}\right)$ & -0.3906 & -7.96 \\
General accessibility of destination $\left(\mathrm{a}_{0 \mathrm{j}}\right)$ & 0.9545 & 7.39 \\
Intrazonal $\left(\mathrm{x}_{0}\right)$ & 0.8435 & $* * *$ \\
Model statistics & & \\
Log likelihood at zero & -16768.9 & \\
Log likelihood at estimation & -13031.7 & \\
Log likelihood at application & -13085.3 & \\
Rho-squared w.r.t. zero & 0.220 & \\
\hline
\end{tabular}

\section{Validation}

The models' bias constants were adjusted in calibration to reproduce the observed mode shares from the combined survey data and 2006 system ridership for KAT, as noted in the tables. The final modeled mode shares for the work tours described in this paper matched observed shares (the model predicted 98.77, 0.64, and 0.59\% shares for Auto, Transit, and Walk/Bike trips respectively, against observed shares of $98.79,0.62$, and $0.60 \%$ ).

The tour mode choice models were also validated against observed 2006 KAT system ridership. Based on KAT total weekly ridership data for 2006, average weekday ridership was approximately 9,390 unlinked trips per weekday when the University of Tennessee was in session, based on the assumption of an equivalent of 323 weekdays per year (equivalent to the assumption that Saturday has $70 \%$ the ridership of a weekday and Sunday has $50 \%$ of a weekday's ridership). The base year model predicts just over 11,500 trips on transit tours, of which, $60.9 \%$ are actually by transit (this is the trip mode split), yielding just under 7,100 linked transit trips per weekday (the model assumes UT is in session). Assuming 1.3 boardings per linked trip, or three transfers per ten linked trips, this implies that the modeled transit trips correspond to approximately 9,220 unlinked trips. This is in substantial agreement with KAT 9,393 daily unlinked transit trips for 2006 and consistent within the range of reasonable assumptions on equivalent weekdays per year and average number of transfers per linked trip.

For location choice models, calibrations were implemented as noted in tables above, in order to reproduce the observed mean travel time from home for each stop time (trip length in the case of home-based trips) and the observed percentage of intrazonal stops from the combined household travel surveys. In particular, it was generally found necessary to adjust the attractiveness of intrazonal work locations (work locations in the same zone as the residence). The adjustment was necessary not only to reproduce the percentage of intrazonal destinations but also to reproduce the mean travel time from home. Too many or 
Table 4 Selected major intercounty work flows

\begin{tabular}{llcc}
\hline Residence & Workplace & 2000 CTPP & 2006 Modeled \\
\hline Blount & Knox & 13,610 & 16,397 \\
Knox & Anderson & 11,015 & 11,677 \\
Anderson & Knox & 8,114 & 8,694 \\
Sevier & Knox & 6,520 & 5,792 \\
Knox & Blount & 5,329 & 6,569 \\
Loudon & Knox & 4,580 & 7,793 \\
Jefferson & Knox & 4,380 & 2,723 \\
Union & Knox & 3,558 & 3,795 \\
Grainger & Knox & 2,064 & 1,778 \\
Jefferson & Sevier & 1,755 & 2,182 \\
\hline
\end{tabular}

too few intrazonal stops in the estimated model was generally the primary reason of too short or too long average travel times from home.

County level work flows from the model were compared to the 2000 Census Transportation Planning Package's journey to work (JTW) flows. As shown in Table 4, the modeled flows closely match most of the observed work flows from the census, plus small increases to account for growth between 2000 and 2006.

\section{Conclusions}

The main lesson of this work is that the hierarchical ordering of decision nesting trees in a complete travel demand model is important, and that employing a reverse ordering can be a good choice, especially in metropolitan areas that are similar to Knoxville. We have presented the results for models of tour mode choice and destination choice for work tours in Knoxville. The parameters of these models are consistent with the presumption of a greater propensity to change destination than to change mode, and those parameters required no exogenous restriction or adjustment in order to remain consistent with utility maximization theory.

The traditional ordering of the choice hierarchy may still be useful, and possibly superior, in many cases, particularly larger cities with higher population densities, more well developed transit operators, and the presence of substantial populations of choice riders on transit. Indeed, the results in this paper merely suggest that the reverse hierarchy might provide a good predictive tool for some cities.

Much research into these relationships remains to be done, as the paucity of literature on this topic indicates. Where more substantial resources are available, an examination of the relative properties of the models in a FIML environment should be undertaken, as the sequential models illustrated in this work are an inferior substitute for such complete models. And of course, the anecdotal evidence of a single medium-sized American city does not demonstrate any general principles for the formulation travel models; we leave for the future a direct comparison of forward and reverse models for travel demand forecasting in other cities both large and small. 
Acknowledgements Part of this research was conducted by Bernardin, Lochmueller \& Associates on behalf of the Knoxville Regional Transportation Planning Organization, who provided the underlying data. We would also like to thank Laurie Garrow, Tom Rossi, and three anonymous reviewers for their helpful comments.

\section{References}

Abrahamsson, T., Lundqvist, L.: Formulation and estimation of combined network equilibrium models with applications to Stockholm. Transp. Sci. 33(1), 80-100 (1999)

Ben-Akiva, M.: Structure of passenger travel demand models. Transp. Res. Rec. 526, $26-42$ (1974)

Bernardin, V.L.: A trip-based travel demand framework consistent with tours and stop interaction. Ph.D. Dissertation, Northwestern University (2008)

Bernardin, V.S., Koppelman, F.S., Boyce, D.: Enhanced destination choice models incorporating agglomeration related to trip chaining while controlling for spatial competition. Transp. Res. Rec. 2132, 143151 (2009)

Bowman, J.L., Ben-Akiva, M.E.: Activity-based disaggregate travel demand model system with activity schedules. Transp. Res. A 35(1), 1-28 (2001)

Boyce, D.: Is the Sequential Travel Forecasting Paradigm Counterproductive? J Urban Plan. Dev. 128(4), 169-183 (2002)

Bradley, M., Bowman, J.L.: A summary of design features of activity-based microsimulation models for US MPOs. In: Conference on innovations in travel demand modeling, Austin, TX, 2006

Debrezion, G., Pels, E., Rietveld, P.: Modelling the joint access mode and railway station choice. Transp. Res. E 45(1), 270-283 (2009)

ELM-Works LLC: ELM version 1.0, 2009

Fotheringham, A.S.: Some theoretical aspects of destination choice and their relevance to productionconstrained gravity models. Environ. Plan. A 15, 1121-1132 (1983)

Fotheringham, A.S.: Modelling hierarchical destination choice. Environ. Plan. A 18, 401-418 (1986)

Hensher, D.A.: Sequential and full information maximum likelihood estimation of a nested logit model. Rev. Econ. Stat. 68(4), 657-667 (1986)

Jonnalagadda, N., Freedman, J., Davidson, W.A., Hunt, J.D.: Development of microsimulation activitybased model for San Francisco: destination and mode choice models. Transp. Res. Rec. 1777, 25-35 (2001)

Kitamura, R., Kermanshah, M.: Sequential model of interdependent activity and destination choices. Transp. Res. Rec. 987, 81-89 (1984)

Koppelman, F.S., Wen, C.-H.: Alternative nested logit models: structure, properties and estimation. Transp. Res. B 32(5), 289-298 (1998)

Lerman, S.R.: Location, housing, automobile ownership, and mode to work: a joint choice model. Transp. Res. Rec. 610, 6-11 (1976)

Miller, E.J., Roorda, M.J., Carrasco, J.A.: A tour-based model of travel mode choice. Transportation 32(4), 399-422 (2005)

Nerella, S., Bhat, C.R.: Numerical analysis of effect of sampling of alternatives in discrete choice models. Transp. Res. Rec. 1894, 11-19 (2004)

NuStats: 2000 Knoxville urban area household travel behavior study. Final Report. Knoxville Regional Transportation Planning Organization, Knoxville, TN (2001)

NuStats: 2008 East Tennessee household travel survey. Final Report. Knoxville Regional Transportation Planning Organization, Knoxville, TN (2008)

Richards, M.G., Ben-Akiva, M.E.: A simultaneous destination and mode choice model for shopping trips. Transportation 3(4), 343-356 (1974)

Siegel, J.D., De Cea, J., Fernandez, J.E., Rodriguez, R.E., Boyce, D.: Comparisons of urban travel forecasts prepared with the sequential procedure and a combined model. Netw. Spat. Econ. 6(2), 135-148 (2006)

Vrtic, M., Axhausen, K.W.: The impact of tilting trains in Switzerland: a route choice model of regionaland long distance public transport trips. In: 82nd annual meeting of the transportation research board, Washington, DC, 2008

Yagi, S., Mohammadian, A.K.: Joint models of home-based tour mode and destination choices: applications to a developing country. Transp. Res. Rec. 2076, 29-40 (2008) 


\section{Author Biographies}

Jeffrey P. Newman earned a Ph.D. from Northwestern University in 2008, and a MPA from Cornell University in 1999. He has been a research scientist at l'École Polytechnique Fédérale de Lausanne in Switzerland, and currently fills that position at Georgia Tech. In addition, he is a partner and principle programmer at ELM-Works, a discrete choice modeling software firm.

Vincent L. Bernardin, Jr. is Chief of Transportation Modeling for Bernardin, Lochmueller \& Associates where he has worked since 2002. He received his Ph.D. from Northwestern University in 2008. His research has focused primarily on developing advanced trip-based travel models consistent with tours and tripchaining effects. 